Check for updates

Cite this: Sustainable Energy Fuels, 2019, 3, 2111

Received 13th March 2019

Accepted 20th May 2019

DOI: $10.1039 / c 9 s e 00161 a$

rsc.li/sustainable-energy

\section{Making an ultralow platinum content bimetallic catalyst on carbon fibres for electro-oxidation of ammonia in wastewater $\dagger$}

\author{
A. M. Pourrahimi, (D) *ad R. L. Andersson, ${ }^{a}$ K. Tjus, ${ }^{\text {b } ~ V . ~ S t r o ̈ m, ~}{ }^{c}$ A. Björk (D) *b \\ and R. T. Olsson (D) *a
}

Electrocatalysis of wastewater containing ammonia is a promising alternative to chemical and biological water purification for several reasons, one being that energy-rich hydrogen gas is generated as a byproduct while the reaction can be strictly controlled to meet demands. An objective has been to reduce the loading of expensive platinum (Pt) in the catalyst electrodes, and to reduce the poisoning of the metal surface during the electrolysis. Herein, the co-deposition of a copper-platinum (Cu-Pt) bimetallic alloy onto carbon filaments, stripped from their polymeric coating, is shown to give an electrocatalytic performance superior to that of pure Pt at a content of less than $3 \mathrm{wt} \% \mathrm{Pt}$. The key to the enhanced performance was to take advantage of micrometer-sized carbon filaments to distribute a very large bimetallic alloy surface uniformly over the filaments. The $\mathrm{Cu}$-Pt-alloy-coated filaments also suffer less electrode poisoning than pure $\mathrm{Pt}$, and are bonded more strongly to the carbon fibre due to better mechanical interlocking between the bimetallic alloy and the carbon filaments. High-resolution electron microscopy studies combined with a tuned electro-deposition process made it possible to tailor the catalyst micro/nano morphology to reach a uniform coverage, surrounding the entire carbon filaments. The results are promising steps towards large-scale wastewater treatment, combined with clean energy production from regenerated hydrogen.

\section{Introduction}

Ammonia enters our water resources via municipal effluent discharges and contributes to the eutrophication of rivers, lakes and coastal waters. Aquatic organisms cannot excrete high concentration of ammonia from wastewater leading to a toxic buildup in internal tissues, and ultimately death, i.e. contrary to other forms of nitrogen. ${ }^{1}$ The toxicity of ammonia increases with increasing $\mathrm{pH}$ and temperature. ${ }^{2}$ According to the Swedish Environmental Protection Agency (EPA), the highest concentration in effluents should be $10 \mathrm{ppm}$, whereas an acute criterion of $17 \mathrm{ppm}$ total ammonia nitrogen (TAN) at pH 7 and $20{ }^{\circ} \mathrm{C}$ has been recommended by EPA in the United States., ${ }^{\mathbf{1 3}}$ Ammonia removal is, therefore, a crucial process in large

${ }^{a}$ Department of Fibre and Polymer Technology, School of Chemical Science and Engineering, KTH Royal Institute of Technology, Stockholm, Sweden. E-mail: ampo@kth.se; rols@kth.se

${ }^{b} I V L$ Swedish Environmental Research Institute, Stockholm, Sweden. E-mail: anders. bjork@ivl.se

${ }^{~}$ KTH Royal Institute of Technology, School of Industrial Engineering and Management, Material Science and Engineering, SE-100 44 Stockholm, Sweden

${ }^{d}$ Department of Chemistry and Chemical Engineering, Chalmers University of Technology, 41296 Göteborg, Sweden

$\dagger$ Electronic supplementary information (ESI) available. See DOI: $10.1039 / \mathrm{c} 9 \mathrm{se} 00161 \mathrm{a}$ wastewater treatment plants (WWTPs), and methods to remove it from wastewater include; nitrification, ${ }^{4-7}$ ion-exchange $e^{\mathbf{8 , 9}}$ and electrolysis. $^{\mathbf{1 0 - 1 3}}$ The most common method of removing ammonia from wastewaters is biological nitrification and denitrification, which removes $50-75 \%$ of the nitrogen species. ${ }^{3}$ A major challenge is the high cost of the ammonia oxidation, the long reaction times and the specific adjustment of the environmental conditions for bacteria growth required, i.e. $\mathrm{pH}$ and temperature. ${ }^{5}$ The nitrifying bacteria growth is sometimes inhibited by organic pollutants, and ion exchange can be used as an alternative method for removal of the ammonium ion. ${ }^{9}$ The estimated annual cost of these processes is $c a$. two billion US dollars worldwide, considering only the most concentrated water streams $\left(500-2000 \mathrm{~g} \mathrm{~m}^{-3}\right)$ of the 22 million tons of ammonia entering our wastewater treatment plants each year. The electrochemical decomposition of ammonia in wastewater plants would, therefore, be attractive since it could simultaneously be used to produce hydrogen using less thermodynamic energy than water electrolysis. ${ }^{\mathbf{1 0 , 1 2 - 1 5}}$ The decomposition of ammonia in an alkaline electrolyte involves the oxidation of the ammonia to nitrogen and the reduction of water to hydrogen, according to the reactions: $:^{10,13}$

(Anode)

$2 \mathrm{NH}_{3}+6 \mathrm{OH}^{-} \rightarrow \mathrm{N}_{2}(\mathrm{~g})+6 \mathrm{H}_{2} \mathrm{O}+6 \mathrm{e}^{-}, E=-0.77 \mathrm{~V} / \mathrm{SHE}(1)$ 


$$
4 \mathrm{OH}^{-} \rightarrow \mathrm{O}_{2}(\mathrm{~g})+4 \mathrm{H}_{2} \mathrm{O}+4 \mathrm{e}^{-}, E=+0.40 \mathrm{~V} / \mathrm{SHE}
$$

(Cathode)

$$
2 \mathrm{H}_{2} \mathrm{O}(\mathrm{l})+2 \mathrm{e}^{-} \rightarrow \mathrm{H}_{2}(\mathrm{~g})+2 \mathrm{OH}^{-}, E=-0.83 \mathrm{~V} / \mathrm{SHE}
$$

The oxidation of ammonia in an alkaline medium to generate hydrogen needs a cell potential of $0.06 \mathrm{~V}$ (reaction 1 and 3), while the electrolysis of water in the absence of ammonia needs a higher cell potential according to reactions 2 and 3; i.e. 1.23 V. The electrolysis of ammonia has the additional advantages of low operating temperatures, no hazardous emissions, and responsiveness to different concentrations of ammonia in the wastewater, while making use of hydrogen stored in the ammonia. ${ }^{12,13}$

So far, the noble metal platinum (Pt) has been used as the main component of electrodes for ammonia electro-oxidation and water splitting due to its high electrocatalytic activity, ${ }^{12,16-18}$ but the amount of $\mathrm{Pt}$ required to achieve a reasonable performance has restricted its use in large-scale applications (typically $0.05-34 \mathrm{mg} \mathrm{cm} \mathrm{cm}^{-2}$ ). ${ }^{12}$ A large overpotential for ammonia electro-oxidation is also required, which leads to a loss in electrode efficiency. ${ }^{\mathbf{1 4}}$ The challenge here is to develop electrodes at a reasonable cost, which show a minimum ohmic loss and long-term stability, while ensuring sufficient electro-catalytic activity. ${ }^{12}$ Two ways to solve this problem have been proposed; (i) using a high surface-to-volume support substrate that reduces the catalytic metal to a minimal amount of $\mathrm{Pt}$ while maintaining an extensive reactive surface $;^{\mathbf{1 3 , 1 9 , 2 0}}$ or (ii) alloying Pt with cheaper transition metals, e.g. copper $(\mathrm{Cu}) .{ }^{21}$ Pt-free or Pt-alloyed electrodes based on iridium, ruthenium, rhodium, and palladium metals have also been studied. ${ }^{\mathbf{1 2 , 2 2 - 3 0}}$ These electrodes may perform better than pure Pt electrodes in the electro-oxidation of ammonia, but the preparation costs are even greater. A combination of the two approaches, using small amounts of expensive Pt while alloying more inexpensive compounds on high surface-to-volume support substrates has received less attention. ${ }^{31,32}$ This is partly due to the bottleneck of finding a useful conductive substrate 'templates' that can reliably hold the catalytic metal structures, which are in turn required to be on the micro/ nanoscale to optimize its surface area to mass ratio. ${ }^{33}$

In this work, nano-structured catalytic Pt and bimetallic $\mathrm{Cu}-$ Pt coatings electroplated on carbon fibre filaments have been studied for inexpensive catalysis and electro-oxidation of ammonia in wastewater. The carbon fibres have a high specificsurface-area (ca. $\left.0.4 \mathrm{~m}^{2} \mathrm{~g}^{-1}\right),{ }^{34}$ high stiffness $(\approx 200 \mathrm{GPa})$, and higher mechanical strength $(\approx 3.5 \mathrm{GPa}$ normalized to mass) compared to the metallic high surface-to-volume substrate materials used in industrial electrolysis. ${ }^{35}$ These properties combined with low thermal expansion and high chemical resistance make the carbon fibres interesting as substrates for carrying electrocatalysts in both alkaline and acidic environments. The catalytic metals can be deposited on to carbon structures by wet precipitation using reducing agents, ${ }^{36,37}$ by deposition from the gas phase, ${ }^{38,39}$ and by electrochemical deposition (electroplating). ${ }^{\mathbf{1 3}, \mathbf{4 0 - 4 2}}$ The electroplating technique was chosen because of its inexpensive and versatile water chemistry, which show a potential to be up-scaled for industrial applications, as well as its unique ability to allow coating of complex surfaces. It is demonstrated that controlling the electrodeposition parameters (i.e. applied current, voltage and time) and surface chemistry of the carbon fibres, it is possible to grow morphologies with a high specific catalytic activity. The Pt electrocatalyst gave an electrochemically active surface area (ECSA) of $21 \mathrm{~m}^{2} \mathrm{~g}^{-1}$ for hydrogen generation, and a peak current density of $c a$. $6 \mathrm{~mA} \mathrm{mg} \mathrm{Pt}^{-1}$ during the electro-oxidation of ammonia, although the filament electrodes showed poor mechanical stability. The conditions for Pt deposition were however further used to develop a novel bimetallic $\mathrm{Cu}-\mathrm{Pt}$ alloy with an extremely low content of Pt (3 wt\%), which had almost the same level of catalytic activity as the pure Pt system. In addition, the poisoning effect (the blockage of active surfaces by nitrogen species) was reduced due to the presence of a large amount of copper in the alloy. The presented design reduced the electrode cost dramatically, which allow for upscaling of active catalytic surfaces to be explored in a variety of applications.

\section{Experimental section}

\subsection{Materials}

Copper(II) sulphate pentahydrate $\left(\mathrm{CuSO}_{4} \cdot 5 \mathrm{H}_{2} \mathrm{O}\right.$, ACS reagent, $\geq 99 \%$, AnalaR NORMAPUR), sulfuric acid $\left(\mathrm{H}_{2} \mathrm{SO}_{4}\right.$, ACS reagent, $\geq 95 \%$, Sigma-Aldrich), hydrochloric acid ( $\mathrm{HCl}$, ACS reagent, $37 \% \mathrm{w} / \mathrm{w}, 12.2 \mathrm{M}$, Merck millipore), nitric acid $\left(\mathrm{HNO}_{3}\right.$, analysis EMSURE® ISO, 65\% w/w, 14.6 M, EMD millipore), platinum wire (Pt, $0.5 \mathrm{~mm}$ diameter, $\geq 99.9 \%$, Metalor Technologies, Borås Sweden), potassium hydroxide (KOH, ACS reagent, $\geq 85 \%$, Sigma-Aldrich), and ammonium hydroxide solution (ACS reagent, 28.0-30.0\% $\mathrm{NH}_{3}$ basis, Sigma-Aldrich) were used as received. High resistivity MilliQ water, "ultrapure" water of “Type 1", according to ISO 3696 and ASTM D1193-91 (18.2 Mohm cm at $25{ }^{\circ} \mathrm{C}$ ) was used in all the reactions. Carbon fibres, Pyrofil TR30S 3K $\left(200 \mathrm{mg} \mathrm{m}^{-1}\right.$, density $1790 \mathrm{~kg} \mathrm{~m}^{-3}$, 3000 filaments per bundle, average filament diameter $7 \mu \mathrm{m}$ ) were bought from Easy Composites Ltd, UK. The surface area of the filaments inside the carbon fibres was estimated to $0.33 \mathrm{~m}^{2} \mathrm{~g}^{-1}$, but due to the irregular curvature it was experimentally determined by BET (Brunauer-Emmett-Teller) to be $c a .0 .4 \mathrm{~m}^{2} \mathrm{~g}^{-1} \cdot{ }^{34}$

\subsection{Synthesis of chloroplatinic acid $\left(\mathrm{H}_{2} \mathrm{PtCl}_{6} \cdot \mathbf{6} \mathrm{H}_{2} \mathrm{O}\right)$}

Chloroplatinic acid was prepared by dissolving a Pt wire $(5 \mathrm{~g})$ in boiling aqua regia $(50 \mathrm{ml})$, consisting of concentrated hydrochloric acid (37\%) and nitric acid (65\%) at a volume ratio of $3: 1$ $\left(\mathrm{HCl}: \mathrm{HNO}_{3}\right)$, in a $250 \mathrm{ml}$ glass container equipped with a thermometer, a magnetic stirrer, and a reflux condenser. The gases generated at the exit of the condenser $\left(\mathrm{Cl}_{2}, \mathrm{NOCl}, \mathrm{HCl}\right.$, and NOx) were scrubbed into a cold-water container. The reactor was maintained at a temperature of $80{ }^{\circ} \mathrm{C}$. During the dissolution time $(12 \mathrm{~h})$, it was necessary to add $\mathrm{HCl}$ to compensate for its depletion and evaporation. After dissolution, the acidic mixture was allowed to evaporate until the volume 
reached $10 \mathrm{ml}$ and $30 \mathrm{ml}$ of $\mathrm{HCl}$ was then added. This step was done twice to decompose and remove any remaining nitric acid, evident by the presence of brownish vapour. To avoid decomposition of the chloroplatinic acid into $\mathrm{PtCl}_{4}$, the last $10 \mathrm{ml}$ of the Pt salt solution was allowed to crystallize and further dried and stored under vacuum in a desiccator.

\subsection{Removal of surface polymer sizing from carbon fibres}

Before the electrodeposition, the protective layer of polymer sizing applied as a non-conductive surface coating in the production of the carbon fibres was removed by a shock heattreatment up to $c a$. $750-850{ }^{\circ} \mathrm{C}$ for $10 \mathrm{~s}$. This was performed via resistive heating of the filament bundles by applying 130 $\mathrm{V}_{\mathrm{rms}}(50 \mathrm{~Hz})$ per meter of fibre length, with a variable autotransformer (METREL HSN0203, power: $1.82 \mathrm{kVA}$ ), Fig. 1 (top). The current was 7 A per fibre bundle, each consisting of 3000 filaments with a diameter of $7 \mu \mathrm{m}$ resulting in a current density of $61 \mathrm{~A} \mathrm{~mm}^{-2}$.

\subsection{Electroplating of metals ( $\mathrm{Cu}$ and $\mathrm{Pt}$ ) onto carbon fibre}

The electrochemical deposition of metals onto the carbon filaments was carried out at room temperature using a Keithley 2450 Source Meter in a typical three-electrode setup. A $250 \mathrm{ml}$ cylindrical beaker with an inner diameter of $60 \mathrm{~mm}$ and a height of $88 \mathrm{~mm}$ was used, in combination with an $\mathrm{Ag} / \mathrm{AgCl}$ (RE-1S reference electrode, length: $52 \mathrm{~mm}$, OD: $4.5 \mathrm{~mm}$, electrolyte $3 \mathrm{M} \mathrm{NaCl}$ ) as a reference electrode, Fig. 1 (top). The working electrode was $50 \mathrm{~mm}$ of carbon fibre consisting of the ca. 3000 carbon filaments placed vertically in the middle of the beaker. The counter electrode was $1 \mathrm{~m}$ of Pt wire $(0.5 \mathrm{~mm})$, spirally mounted on the inner surface of the beaker. The deposition process was carried out and optimized at room temperature by applying either a constant voltage (within a range +0.2 to $-1 \mathrm{~V}$ ) or a constant current $(-5$ to $-100 \mathrm{~mA})$. The concentrations of the metal-salt solutions were varied between 2 to $10 \mathrm{mM}$ for $\mathrm{Pt}$ and $\mathrm{Cu}$, respectively, and the $\mathrm{pH}$ was adjusted with sulfuric acid. The electroplated carbon filaments were washed with deionized water and dried at $80{ }^{\circ} \mathrm{C}$ overnight. The electroplating of the metals on the carbon filaments was assessed by cyclic voltammetry (scanning rate $20 \mathrm{mV} \mathrm{s}^{-1}$ within the range from +1 to $-1 \mathrm{~V}$ ) in the similar electrochemical set-up.

\subsection{Characterization}

A field emission scanning electron microscope (SEM; Hitachi S4800) connected to an energy dispersive spectrometer (EDS) (Oxford Instruments, UK) was used to assess the morphology and elemental composition of the coatings.

$\mathrm{X}$-ray diffractograms of the powder samples were recorded at room temperature using a PANalytical X'pert Pro MPD X-ray diffraction (XRD) diffractometer equipped with a $\mathrm{Cu}-\mathrm{K} \alpha$ source (wavelength $=1.54178 \AA$ ), using a $2 \theta$ step size of $0.017^{\circ}$ at a generator voltage of $45 \mathrm{kV}$ and a current of $40 \mathrm{~mA}$. The crystal

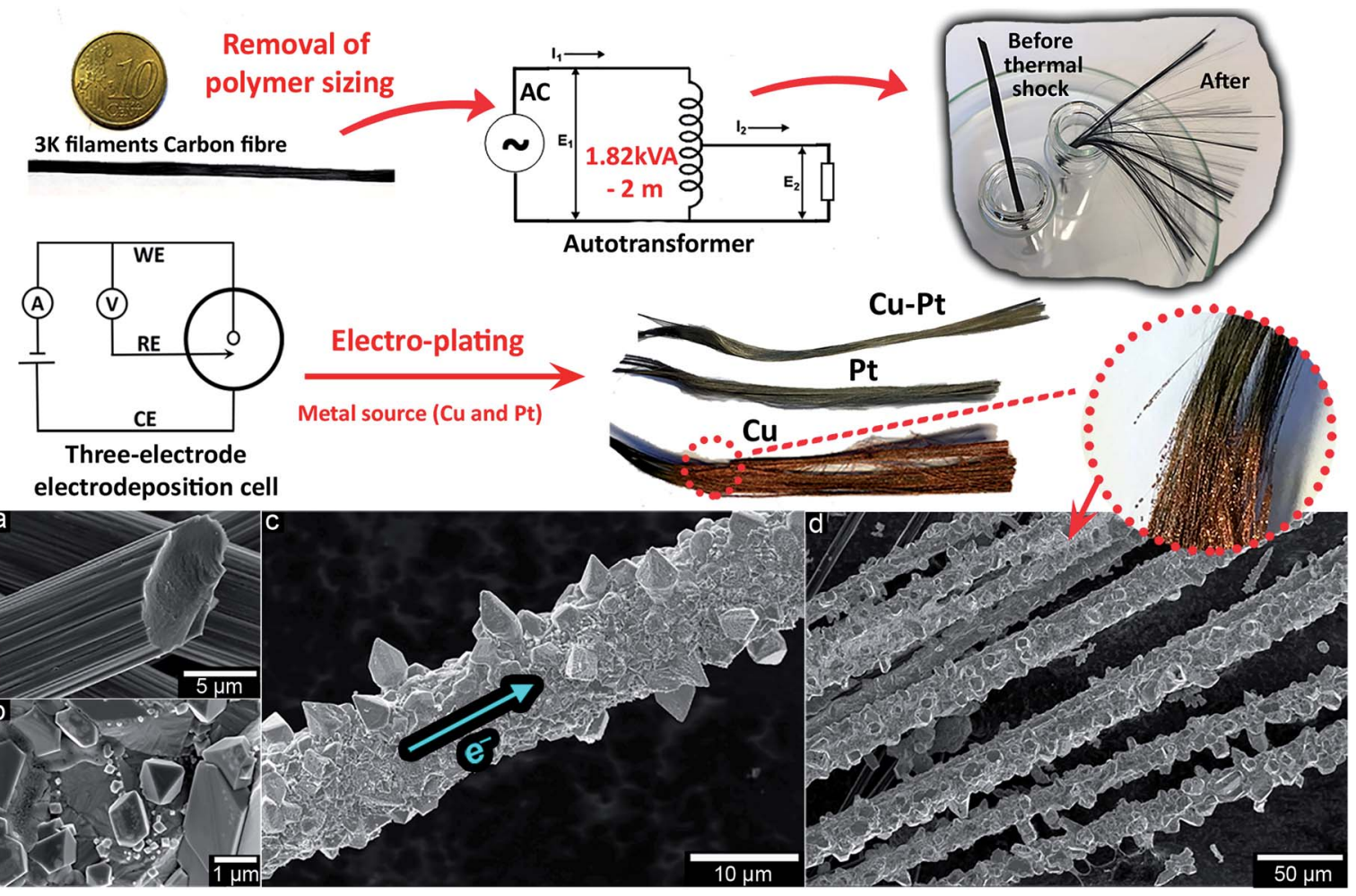

Fig. 1 (top) The schematic experimental overview for removal of non-conductive polymer sizing and activation of the ca. 3000 filaments in one carbon fibre, followed by electrodeposition of $\mathrm{Cu}$, Pt and $\mathrm{Cu}$-Pt on carbon filaments; (below) the SEM images of (a) a pristine single filament of carbon fibre, and $(b-d)$ electroplated copper on carbon filaments at different magnifications (from nano- to micro-structures). A 10 cent coin is shown to indicate the approx. width of a carbon fibre containing ca. 3000 filaments. 
size $(D)$ and crystal interplanar distance $(d)$ respectively were obtained from the Scherrer and Bragg equations:

$$
\begin{aligned}
& D=\frac{k \lambda}{\beta \cos \theta} \\
& d=\frac{\lambda}{2 \sin \theta}
\end{aligned}
$$

where $k$ is a shape factor equal to $0.89, \lambda$ is the characteristic wavelength of the $\mathrm{Cu}-\mathrm{K} \alpha$ radiation $(0.154178 \mathrm{~nm}), \theta$ is the Bragg angle and $\beta$ is the peak width at half-maximum in radians.

X-ray photoelectron spectroscopy (XPS) spectra were collected with a Kratos Axis Ultra DLD electron spectrometer using a monochromatic $\mathrm{Al} \mathrm{K \alpha}$ source operating at $150 \mathrm{~W}$. An analyzer pass energy of $160 \mathrm{eV}$ was used to acquire wide spectra and a pass energy of $20 \mathrm{eV}$ was used for individual photoelectron lines. Since the carbon fibre samples were relatively large and heterogeneous in macrostructures and conductivity, the surface potential was stabilized using a spectrometer charge neutralization system. ${ }^{43}$ The spectra were processed with the Kratos software.

\subsection{Electrochemical measurements on ammonia solutions}

The electrochemical measurements were performed with the electroplated carbon fibre filaments as working electrodes in an electrolyte ammonia solution $\left(0.1 \mathrm{M} \mathrm{NH}_{3}+1 \mathrm{M} \mathrm{KOH}\right)$ at room temperature in a typical three-electrode setup $(250 \mathrm{ml}$ cylindrical beaker, $60 \mathrm{~mm}$ inner diameter, $88 \mathrm{~mm}$ height), using a Keithley 2450 Source Meter. The Pt wire (1.5 g) was used as the counter-electrode. Both working and counter electrodes were immersed in the same electrolyte solution, and separated by open plastic cylinders. In this way, the gas bubbles produced at the electrodes were not accessible to each another. The reference electrode was of standard $\mathrm{Hg} / \mathrm{HgO}$ type $\left(\mathrm{KNO}_{3} 1 \mathrm{M}\right.$ inner electrolyte solution, XR440, Radiometer). The cyclic voltammetry measurements were performed in the presence and absence of ammonia at scanning rates of -2 to $-200 \mathrm{mV} \mathrm{s}^{-1}$ within the range of -1 to $0.4 \mathrm{~V}$.

\section{Results and discussion}

\subsection{Carbon fibre treatment and electrodeposition onto carbon filaments}

Fig. 1 (top) shows a general scheme for the carbon fibre electrode preparation, and three separately coated carbon fibres electrodeposited with $\mathrm{Cu}-\mathrm{Pt}, \mathrm{Pt}$, and with $\mathrm{Cu}$ alone. The pristine carbon fibres contained $c a .3000$ filaments with an average diameter of $7 \mu \mathrm{m}$. These bundles of filaments were coated as hanging entities in the center of the electrodeposition cell (Fig. 1). Scanning electron micrographs of the carbon fibres prior to and after electrodeposition of pure $\mathrm{Cu}$ are shown in Fig. 1a-d. Before electroplating, an important pre-treatment step had to be carried out in order to activate the fibre surfaces, since commercial carbon fibres have a polymer coating (sizing), usually of epoxy resin on their surfaces. This is essential for the bundling and handling of the fibres during manufacture, but it also acts as an electrical insulator and chemical passivator. ${ }^{44}$ The surface conductivity is therefore considerably lower than that in the out-of-plane and in-plane graphite directions within the filaments (transverse and along the filaments), limiting their application in electrochemistry unless the sizing is effectively removed. ${ }^{45}$ The de-sizing of fibres had previously been carried out by thermal or chemical treatment. ${ }^{46}$ In addition to the physical removal of the sizing, however, these treatments were found to damage either the bulk or the surface of the carbon fibres and lowered the filament conductivity, possibly due to changes in the fibre microstructure. In contrast, an electrical shock heat-treatment by application of $61 \mathrm{~A} \mathrm{~mm}^{-2}$ current resulted in a power dissipation of ca. $0.3 \mathrm{~W} \mathrm{~m}^{-1}$ per carbon fibre filament, causing a quick decomposition and evaporation of the polymer sizing products at an estimated temperature of $750-850{ }^{\circ} \mathrm{C}$. The conductivity along the filaments after removal of the polymer coating was $1.18 \times 10^{-5} \mathrm{ohm} \mathrm{m}$. For comparison, a perfect single crystal of graphite has been reported to show $1 \times 10^{-6} \mathrm{ohm} \mathrm{m}$ parallel to, and $1 \times 10^{-2} \mathrm{ohm} \mathrm{m}$ perpendicular to the basal plane. ${ }^{47}$ The high electrical conductivity thus appeared to stem from an undistorted dominant graphite crystal orientation along the filaments. The electrical shock treatment also opened up the carbon fibre filament bundles into separate filaments with the potential to be assessed in the electroplating reactions, demonstrated in Fig. 1. The deposited copper or platinum metal could be detected by their red-brown and grey-white colour, while the electroplated $\mathrm{Cu}-\mathrm{Pt}$ alloy on the carbon fibre showed an intermediate colour (Fig. 1). Fig. 1b-d shows the marked changes in morphology of the copper-electroplated carbon filaments, used in the initial screening of the most useful electroplating condition. Lower magnifications revealed the ability of the copper to uniformly cover the filaments with an average thickness of 1-2 $\mu \mathrm{m}$ (Fig. 1c and d) when an excess of $10 \mathrm{mM}$ metal solution was used during 2 hours of electroplating. The copper coverage consisted of polycrystalline and multi-faceted copper grains with sizes ranging from nano- to micrometer.

Fig. 2a shows the multi-cyclic voltammograms measured in an aqueous $\mathrm{CuSO}_{4}$ solution $(10 \mathrm{mM})$, which were scanned during deposition and dissolution onto the carbon filaments. The $\mathrm{pH}$ was adjusted to 1 and the scanning potential range was set from +1 to $-1 \mathrm{~V}$ to ensure complete deposition and dissolution of copper metal. During the first cathodic scan, the copper deposition peak showed an onset potential of $c a$. $-50 \mathrm{mV}$ and a peak at $c a .-300 \mathrm{mV} v s$. $\mathrm{Ag} / \mathrm{AgCl}$ due to the reduction of copper ions. In the reversal sweeps, the cathodic current (absolute value) gradually decreased until it crossed 0.0 $\mathrm{A}$ at $c a .-50 \mathrm{mV}$ where the anodic reaction started due to the dissolution of the deposited copper. The corresponding anodic peak was observed at $c a .+500 \mathrm{mV}$, and the current past the peak was not $0.0 \mathrm{~A}$ at the vertex $+1 \mathrm{~V}$, indicating that the oxidative dissolution of metallic copper at the carbon filament surface was not complete. ${ }^{48}$ Residual metallic copper on the carbon fibre surface could thus act as nuclei for further electrodeposition via layer-by-layer growth, which was indicated by an increase in the cathodic and anodic current peaks, and a shift in the potential to higher voltages during the subsequent cycles. 

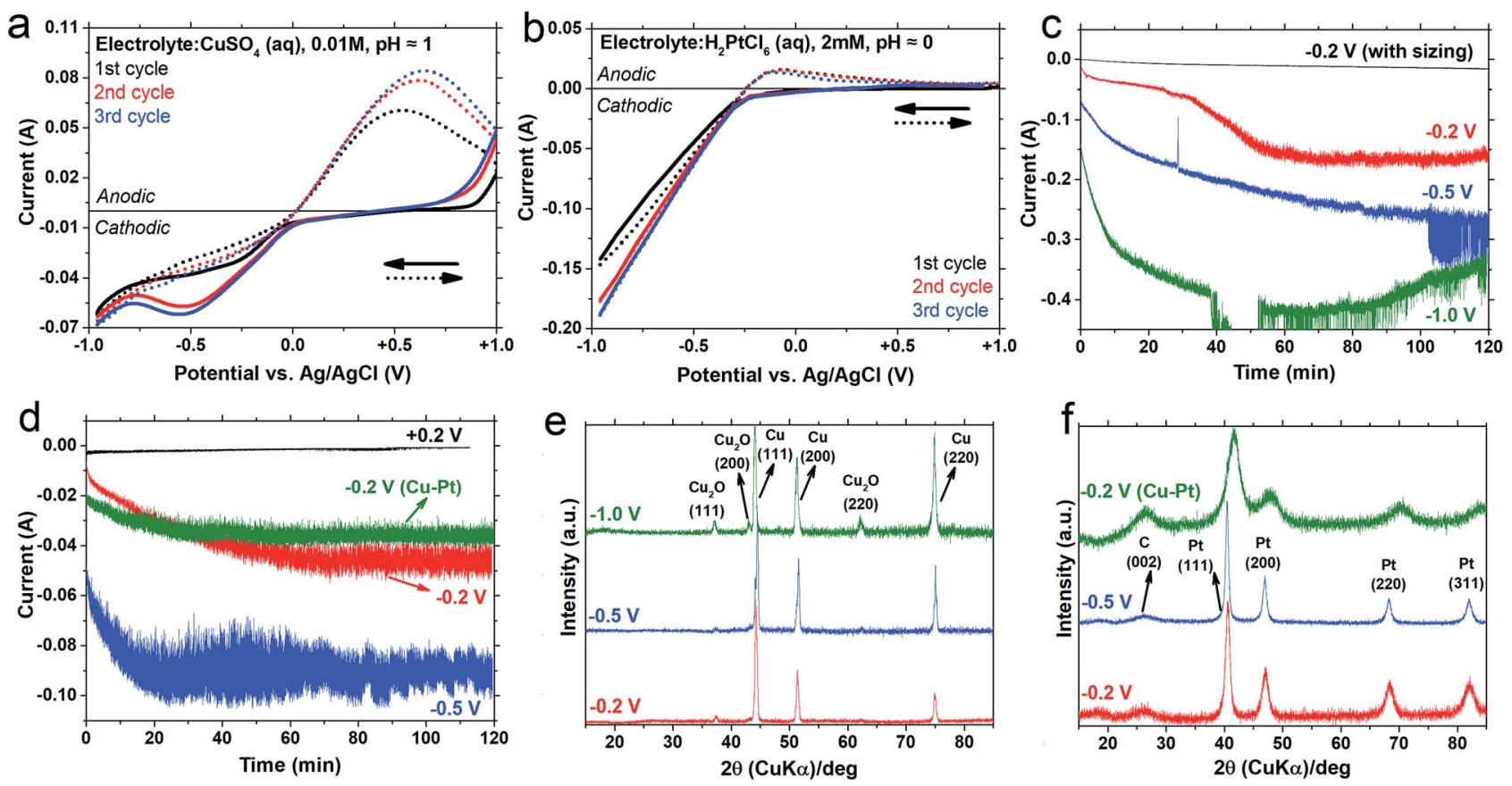

Fig. 2 Electrochemical measurements of the deposition of copper, platinum and their alloy onto 50 mm carbon fibres filaments, together with the electroplated crystal structure; cyclic voltammogram scans without a polymer coating for $\mathrm{Cu}$ and Pt, with a sweep rate of $20 \mathrm{mV} \mathrm{s}{ }^{-1}$ at room temperature ( $\mathrm{a}$ and $\mathrm{b}$ ); cathodic current-time profile during $2 \mathrm{~h}$ potentiostatic deposition of $\mathrm{Cu}$ and $\mathrm{Pt}(\mathrm{c}$ and $\mathrm{d})$ ), together with $\mathrm{X}$-ray diffractograms of carbon fibres after $2 \mathrm{~h}$ potentiostatic deposition of $\mathrm{Cu}$ and $\mathrm{Pt}$ at different voltages vs. $\mathrm{Ag} / \mathrm{AgCl}(\mathrm{e}$ and f). The combined $\mathrm{Cu}-\mathrm{Pt}$ deposition was made at $-0.2 \mathrm{~V}$ from a solution of $0.01 \mathrm{M} \mathrm{CuSO}_{4}$ and $2 \mathrm{mM} \mathrm{H}_{2} \mathrm{PtCl}_{6}$, adjusted to $\mathrm{pH} \approx 0$, and marked as (Cu-Pt) in (d and f).

For comparison, multi-cyclic voltammetry was carried out under the same conditions for electrodeposition of the copper onto a flat graphite substrate, Fig. S2a. $\dagger$ The cyclic voltammograms for the deposition and dissolution of copper on the graphite surface showed a more symmetrical pattern than the carbon filament substrate, indicating typical diffusion growth characteristics. $^{40}$ The cathodic and anodic peaks for the graphite substrate were observed at lower values of respectively $-220 \mathrm{mV}$ and $+185 \mathrm{mV}$ than for the carbon filament substrates (cf. Fig. 2a and S2a $\dagger$ ). In contrast to the carbon filament case, the subsequent voltammograms were almost superimposed on the first cycle in the case of the flat graphite substrate. It was suggested that these differences were due to different ion diffusion mechanisms onto substrates with the different surface areas and different curvatures ${ }^{40}$ and/or crystallographic substratemetal misfits. ${ }^{48}$ It was therefore concluded that the high specific surface area and curvature of the carbon filament substrates affected and reduced the local ion diffusion, and the rates of electrodeposition and dissolution, the explanation being that the deposition coverage during the first cycle was incomplete, so that increased deposition could occur during the subsequent cycles due to the already nucleated metal species. Another possibility is that the carbon filaments were slightly rough and affected the layer-by-layer electrodeposition mechanism.

Fig. $2 \mathrm{~b}$ shows the multi-cyclic voltammograms for the electrodeposition of the aqueous chloroplatinic acid solution with the $\mathrm{pH}$ adjusted to about 0 . A lower $\mathrm{pH}$ and a lower concentration were chosen for the platinum deposition due to its noble metal character. In the first negative sweep, the reduction of $\mathrm{Pt}$ ions on the carbon filament surfaces started at $c a .-200 \mathrm{mV}$ and the cathodic current increased linearly with the applied potential until vertex $-1 \mathrm{~V}$, but atomic hydrogen re-deposition ${ }^{49}$ occurred together with the Pt deposition. In the reversal sweep, the cathodic current decreased with the same slope to $0.0 \mathrm{~A}$. The anodic peak at $c a .-100 \mathrm{mV}$ and its shoulder were thus related respectively to the ionisation of hydrogen adsorbed on the deposited $\mathrm{Pt}$ and to the slight formation of surface Pt-oxide species $\left(\mathrm{PtO}, \mathrm{PtO}_{2}, \mathrm{Pt}(\mathrm{OH})_{2}\right){ }^{49}$ In subsequent cycles, the cathodic current increased more sharply because the platinum deposited in the first cycle was not dissolved during the anodic sweep. In the case of copper, only small remains of $\mathrm{Cu}$ acted as a substrate for further deposition in subsequent cycles.

Fig. $2 \mathrm{c}$ and $\mathrm{d}$ show the current-time profile during the potentiostatic (vs. $\mathrm{Ag} / \mathrm{AgCl})$ reduction of copper and platinum ions, respectively, as discussed in Fig. $2 \mathrm{a}$ and $\mathrm{b}$. In order to eliminate the effect of ion diffusion, the electrolyte solutions were stirred during the deposition, ${ }^{50}$ and the cyclic voltammetry under stirring is shown in Fig. S2b and c. $\dagger$ According to Faraday's law, the weight of plating deposited on the cathode is a linear function of both time and current. In a typical carbon filament electroplating, however, the cathodic current for both electrolyte systems increased sharply during the first $20 \mathrm{~min}$, which is indicative of a fast nucleation and growth; whereafter the current increased only gradually. The cathodic current for the combined aqueous chloroplatinic acid and copper sulphate solution at $\mathrm{pH} \approx 0$ was more monotonous than that for the chloroplatinic acid (see Cu-Pt in Fig. 2d), which was indicative of a more controlled nucleation and growth for the 
electroplating of the copper-platinum binary system. Fig. S1† shows the carbon filament coatings corresponding to the different deposition currents, and Fig. 2c shows that the carbon fibres with the intact polymer sizing showed a significantly lower cathodic current than the carbon fibre with removed polymer sizing, i.e. during deposition with the same applied potential of $-0.2 \mathrm{~V}$, and almost no $\mathrm{Cu}$ coverage occurred. In fact, the high-temperature removal of insulating polymer sizing not only extensively increased the out-of-plane conductivity of the carbon fibres, but was vital for the filaments to function as a deposition substrate. Reducing the thermal treatment only to an extent where the filaments were only partially glowing at lower temperature negatively affected the ability of the fibres to become entirely embedded in the catalytic coatings.

Fig. 2e and $\mathrm{f}$ show the X-ray diffractograms of the electrodeposited carbon fibre samples after $2 \mathrm{~h}$ potentiostatic deposition in aqueous solutions of respectively copper sulphate and chloroplatinic acid (with conditions stated in Fig. 2a and b). Both $\mathrm{Cu}$ and Pt electrodeposited on carbon fibres showed clear diffraction peaks corresponding to the cubic crystal structure lattice planes with a corresponding Miller index of $(h k l)$. The electrodeposited samples from the $\mathrm{Cu}^{2+}$ electrolyte solution showed mainly a metal phase together with a small amount of copper(I) oxide (Fig. 2e). According to the Scherrer equation (eqn (4)), based on the peak at $44^{\circ}$ corresponding to the (111) plane, the sizes of the copper crystals were 18.2, 26.2 and $16.9 \mathrm{~nm}$ for applied potentials of $-0.2,-0.5$ and $-1.0 \mathrm{~V}$, respectively. The oxide phase that formed on the surface of copper crystals in the acidic environment, ${ }^{51}$ was thus indicative of that the smaller copper crystals with a larger specific surface area were more prone to oxidize at the higher potential $(-1.0 \mathrm{~V})$. The electrodeposited samples from the chloroplatinic acid solution showed a pure platinum metal phase within the $3 \mathrm{~nm}$ detection limit (Fig. 2f). ${ }^{52,53}$ The X-ray diffractograms for samples containing $\mathrm{Pt}$ also showed a peak at $26^{\circ}$ corresponding to the (002) crystal plane of carbon fibres. The relatively high intensity of this peak indicated a smaller Pt metal deposit after electroplating than the copper electrodeposition ( $c f$. Fig. 2e and f). The calculated crystal sizes based on the peak at $44^{\circ}$ corresponding to the Pt (111) plane were 10.0 and $13.4 \mathrm{~nm}$ respectively for applied potentials of -0.2 and $-0.5 \mathrm{~V}$.
Fig. 2f also shows that the simultaneous deposition of the two metals $(\mathrm{Cu}-\mathrm{Pt}$ binary system at an applied electrodeposition voltage of $-0.2 \mathrm{~V}$ ) revealed a crystal size of $3.6 \mathrm{~nm}$, which is much smaller than that of the pure $\mathrm{Cu}$ and Pt electrodeposited samples. A unique feature of the $\mathrm{Cu}-\mathrm{Pt}$ binary diffractograms was that the diffraction peaks were located at diffraction angles between those of pure $\mathrm{Cu}$ and $\mathrm{Pt}$ systems, indicating that the $\mathrm{Pt}$ and $\mathrm{Cu}$ atoms were randomly distributed in a new cubic superlattice with a different intermediate interplanar distance according to the Bragg equation (eqn (5)). ${ }^{54}$

To gain more information regarding the surface composition of the prepared electrodes, the $\mathrm{Pt}$ and $\mathrm{Cu}-\mathrm{Pt}$ electrodeposited carbon fibre samples were examined with high-resolution XPS (Fig. 3), which measures the kinetic energy and number of electrons that escape from up to $10 \mathrm{~nm}$ of the samples. Fig. $3 \mathrm{a}$ shows the $P t 4 \mathrm{f}_{7 / 2}$ spectrum of Pt electrodeposited carbon fibres deconvoluted into one intensive main peak at $71.2 \mathrm{eV}$ assigned to metallic Pt, together with weaker peaks at 72.0 and $73.7 \mathrm{eV}$ attributed to $\mathrm{Pt}$ in $\mathrm{Pt}(\mathrm{OH})_{2}$ and $\mathrm{PtO}$ oxidized states. ${ }^{55}$ The $\mathrm{Cu}-\mathrm{Pt}$ electrodeposited samples showed a lower intensity for the peaks assigned to Pt species than the Pt electrodeposited samples, indicating that only $3 \mathrm{wt} \%$ of the platinum atoms were at the surface (Fig. 3b), although the EDS results indicated a higher Pt content in the bulk, which is discussed later in Fig. 7h. The peaks in the $\mathrm{Cu} 3 \mathrm{p}$ region suggested that metal atoms were doped into the copper lattice, ${ }^{56}$ and that a $\mathrm{Cu}-\mathrm{Pt}$ superlattice was formed. The $\mathrm{Cu} 2 \mathrm{p}$ spectrum of the binary $\mathrm{Cu}-\mathrm{Pt}$ sample also showed intense peaks from $\mathrm{Cu}^{2+}$ and only a very small fraction of metallic $\mathrm{Cu}$ was detected, Fig. 3c. The presence of a large amount of doped $\mathrm{Cu}^{2+}$ was confirmed by the presence of satellite peaks that suggested that platinum atoms were successfully alloyed with copper atoms. The absence of metallic $\mathrm{Cu}$ was further confirmed by multi-cyclic voltammetry, which was carried out by electrodepositing the $\mathrm{Cu}-\mathrm{Pt}$ binary system on the carbon fibre in $\mathrm{H}_{2} \mathrm{SO}_{4}$ (aq), $0.5 \mathrm{M}, \mathrm{pH} \approx 0$, Fig. S3. $\dagger$ No sign of electrodissolution or re-electrodeposition of pure $\mathrm{Cu}$ was observed.

\subsection{Morphology of copper electrodeposited on carbon fibres}

The morphology of the electro-plated carbon fibres under various applied potentials (potentiostatic mode) and currents
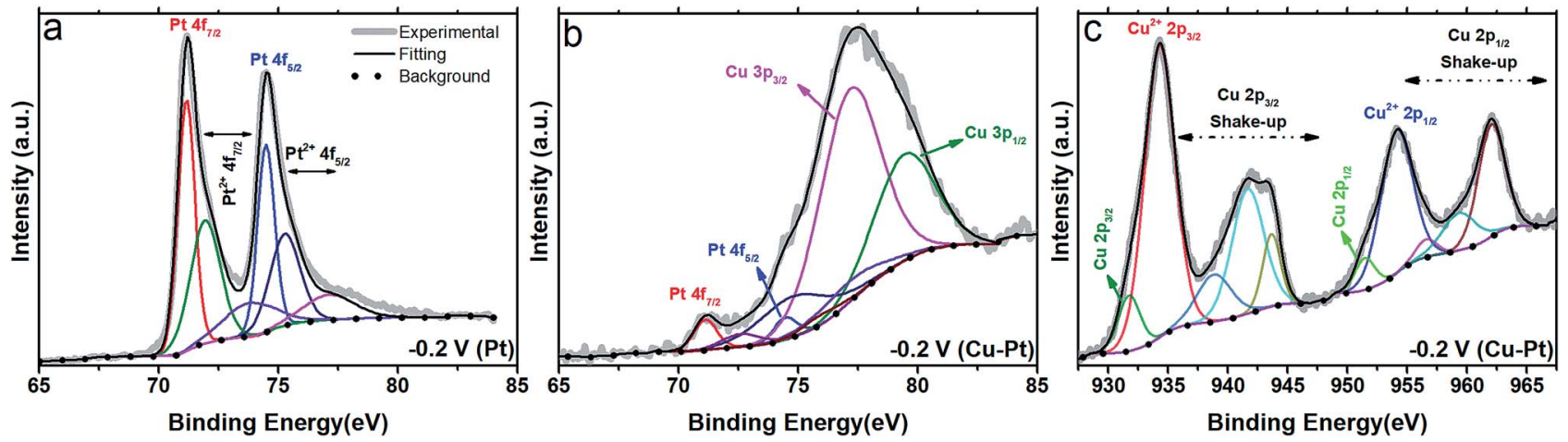

Fig. 3 High-resolution XPS spectra of carbon fibres samples after $2 \mathrm{~h}$ potentiostatic deposition at an applied potential of $-0.2 \mathrm{~V} v \mathrm{vs}$. Ag/AgCl; (a and b) Pt $4 \mathrm{f}$ region of electrodeposited Pt and $\mathrm{Cu}-\mathrm{Pt}$ samples, (c) $\mathrm{Cu} 2 \mathrm{p}$ region of the electrodeposited $\mathrm{Cu}-\mathrm{Pt}$ sample. 


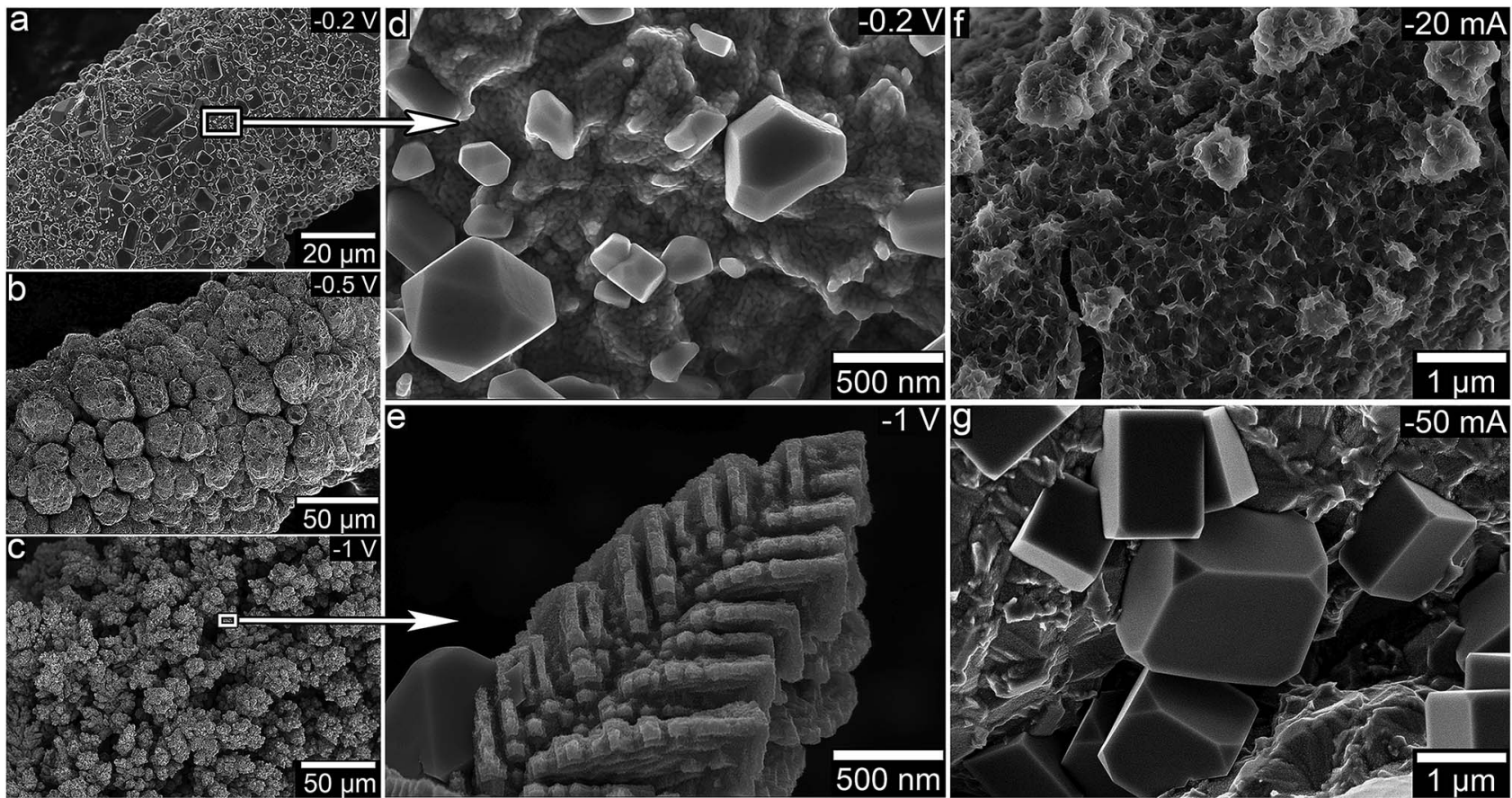

Fig. 4 SEM images of electrodeposited copper on carbon fibres in potentiostatic (applied constant potential vs. Ag/AgCl) and galvanostatic (applied constant current) modes after $2 \mathrm{~h}$.

(galvanostatic mode) is shown in Fig. 4. Fig. 4a-c show the low magnification SEM images of $\mathrm{Cu}$ deposits on $7 \mu \mathrm{m}$ single carbon filament for the three distinctive deposition potentials of $-0.2,-0.5$ and $-1.0 \mathrm{~V}$, respectively, after $2 \mathrm{~h}$. The cathodic current-time profiles during $2 \mathrm{~h}$ and X-ray diffractograms are presented in Fig. $2 \mathrm{~b}$ and c. An applied potential of $-0.2 \mathrm{~V}$ gave the most uniform filament coverage with $c a .10 \mu \mathrm{m}$ average thickness (Fig. 4a), whereas an applied potential of $-0.5 \mathrm{~V}$ resulted in a non-uniform coverage almost twice as thick that contained smaller lump features with sizes ranging from 5 to 50 $\mu \mathrm{m}$ (Fig. 4b). An applied voltage of $-0.5 \mathrm{~V}$ had a current density after $2 \mathrm{~h}$ electroplating twice that of $-0.2 \mathrm{~V}$ (see Fig. $2 \mathrm{~b}$ ), which should indicate a twice as great electroplated $\mathrm{Cu}$ mass on carbon fibres. The greater coverage with the higher applied potential was thus in accordance with Faraday's law. Fig. S4 $\dagger$ shows SEM micrographs of the electroplated layers initially formed at an applied voltage of $-0.5 \mathrm{~V}$, illustrating that the filaments were uniformly covered at the start of the electroplating reaction, as when the applied voltage was lower at -0.2 V. Accordingly, the micron-sized lump features were growing on top of an earlier formed uniform metal layer after longer reaction times. Song et al. $^{\mathbf{4 0}}$ suggested that this was a result of new nucleation sites and growth continuously activated when a more negative potential was applied. Although a higher applied voltage, i.e. $-1.0 \mathrm{~V}$ (far beyond $\mathrm{Cu} / \mathrm{Cu}^{2+}$ equilibrium potential), resulted in much larger current density and electrodeposition at a faster rate, it led to a cathodic current density (absolute value) that started to decrease after $1 \mathrm{~h}$ electrodeposition, Fig. $2 \mathrm{~b}$, due probably to the dissolution and/or detachment of $\mathrm{Cu}$ deposits during the later stages of the electrodeposition. Fig. $\mathrm{S} 5 \dagger$ shows some detached and isolated copper deposits. It was evident that the higher applied voltage resulted in the growth of a nanostructured dendritic copper deposit, and the detachment occurred because the excessive deposition of nanostructured dendritic copper became sensitive to fragmentation from the surface of the carbon fibres. Fig. 4d and e show high magnification micrographs of the electrodeposited copper with a uniform coverage (Fig. 4d) and of the porous and radially grown leaf-like morphologies (Fig. 4e) at applied potentials of -0.2 and $-1.0 \mathrm{~V}$, respectively.

It was reported previously that the electrodeposited copper on substrates (graphite and copper) showed mainly polycrystalline grains with sizes ranging from submicrons to microns. ${ }^{40,48}$ A uniform polycrystalline coverage was also observed in this work with the addition of small facetted morphologies $c a .10 \mathrm{~nm}$ in size for lower applied voltages (Fig. 4d), while dendritic superstructures were obtained at a higher applied voltage (Fig. 4e and S5†). These dendritic copper structures were also reported by Li et al. ${ }^{57}$ as a result of hydrogen evolution together with the reduction of copper ions at the cathode surface at higher applied voltages. Although electrodeposition at a high voltage (close to hydrogen evolution) may seem to be a useful method to develop novel electrode surface with nano/hierarchical structures, these structures are a drawback because of their sensitive nature. A frequent detachment of the developed structures from highly curved carbon fibre surfaces occurred. In contrast, a more reliable and solid uniform copper coverage, surrounding the fibres was always obtained at lower voltages $(-0.2 \mathrm{~V})$.

Fig. 4f and $\mathrm{g}$ show SEM images of $\mathrm{Cu}$ samples electrodeposited in a galvanostatic mode (constant applied current) at respectively -20 and $-50 \mathrm{~mA}$ after $2 \mathrm{~h}$. The corresponding 
cathodic potential $v s$. $\mathrm{Ag} / \mathrm{AgCl}$-time profile during $2 \mathrm{~h}$ is shown in Fig. S6. $\dagger$ An abrupt decrease in the measured voltage (absolute value) occurred at an early stage $(<200 \mathrm{~s})$ and the voltage decreased slightly during the $2 \mathrm{~h}$ of electroplating. The lower applied current, $-20 \mathrm{~mA}$, resulted in a measured voltage of $c a$. $-0.2 \mathrm{~V}$ at the earlier stages ( $<200 \mathrm{~s})$, which finally levelled out at a voltage of $c a .0 .0 \mathrm{~V}$. This constant low applied current resulted in the most uniform $\mathrm{Cu}$ deposits with sizes less than $100 \mathrm{~nm}$, Fig. 4f. It also served to avoid the formation of submicron polycrystalline grains, which were observed on the electrodeposited samples at a low applied voltage, i.e. $-0.2 \mathrm{~V}(c f$. Fig. $2 \mathrm{~d}$ and $\mathrm{f}$ ). Fig. $2 \mathrm{~g}$ shows the presence of submicron cubic polycrystalline grains with truncated corners that were obtained using the higher applied current $(-50 \mathrm{~mA})$. A constant current (galvanostatic mode) during electroplating was thus the most effective way to control the microstructure morphology in the copper electroplating of the carbon filaments.

\subsection{Morphology of platinum electrodeposited onto carbon fibres}

Fig. 5a-c show SEM images of Pt deposits on carbon fibre surface for deposition potentials of $+0.2,-0.2$ and $-0.5 \mathrm{~V}$, respectively ( $v s$. $\mathrm{Ag} / \mathrm{AgCl})$. The corresponding cathodic currenttime profile during $2 \mathrm{~h}$ and X-ray diffractograms are shown in Fig. $2 \mathrm{e}$ and f. A positive applied voltage $(+0.2 \mathrm{~V})$ and a very low cathodic negative current (close to $0.0 \mathrm{~A}$ ) led to a small mass of electroplated Pt formed as spherical nanoparticles on the carbon filament surfaces, Fig. 5a, but this low amount of Pt was could not be detected by X-ray diffraction, ${ }^{52}$ Fig. S7. $\dagger$ A negative voltage of $-0.2 \mathrm{~V}$ resulted in larger micron-sized spherical particles forming inter-particle grain boundaries, Fig. 5b, and an even higher negative voltage, i.e. $-0.5 \mathrm{~V}$, yielded $c a$. 100 times smaller spherical Pt entities (Fig. 5c), but the growth conditions were then very heterogeneous and extended complex dendritic units with sizes close to $10 \mu \mathrm{m}$ were formed (Fig. $5 \mathrm{~d}$ and f). As in the case of the deposition of copper at $-1 \mathrm{~V}$ (Fig. $4 \mathrm{c}$, e and S4†), the platinum entities were composed of leaf-like units within micron-sized superstructures (Fig. $5 \mathrm{~d}$ and f). Fig. 5e shows that the leaves were arranged as highly repetitive dendritic superstructures. In the spherical superstructures (Fig. 5f), the $20 \mathrm{~nm}$ thick leaf-like sheets were more randomly organized, as shown in Fig. 5g. Sheet formation occurred at a lower applied voltage in the Pt system because hydrogen was evolved at a lower voltage in the Pt system than in the case of copper electrodeposition since the platinum itself acts as an electrocatalyst for hydrogen evolution under acidic condition. ${ }^{58}$ These superstructures with specific nano-features could potentially provide more catalytic activity than spherical particles due to their high specific surface area and distinctive atomic termination, ${ }^{59-64}$ but the presence of hydrogen at the surface of the cathode causes some of the deposited metal to detach from the carbon fibre surface (as discussed earlier for the copper system). The application of a voltage close to the hydrogen evolution with a high rate of deposition also makes it difficult to maintain control of the deposited metal morphologies, e.g. when repetitive sample preparation is necessary.

Fig. 6a-c show SEM images of Pt electrodeposited samples in the galvanostatic mode (constant current) after $2 \mathrm{~h}$ for the three deposition currents of $-5,-20$ and $-50 \mathrm{~mA}$, respectively. The corresponding curves of cathodic potential vs. $\mathrm{Ag} / \mathrm{AgCl}$ as a function of time during $2 \mathrm{~h}$ are shown in Fig. 6e. The lower deposition currents, i.e. -5 to $-20 \mathrm{~mA}$, resulted in spherical
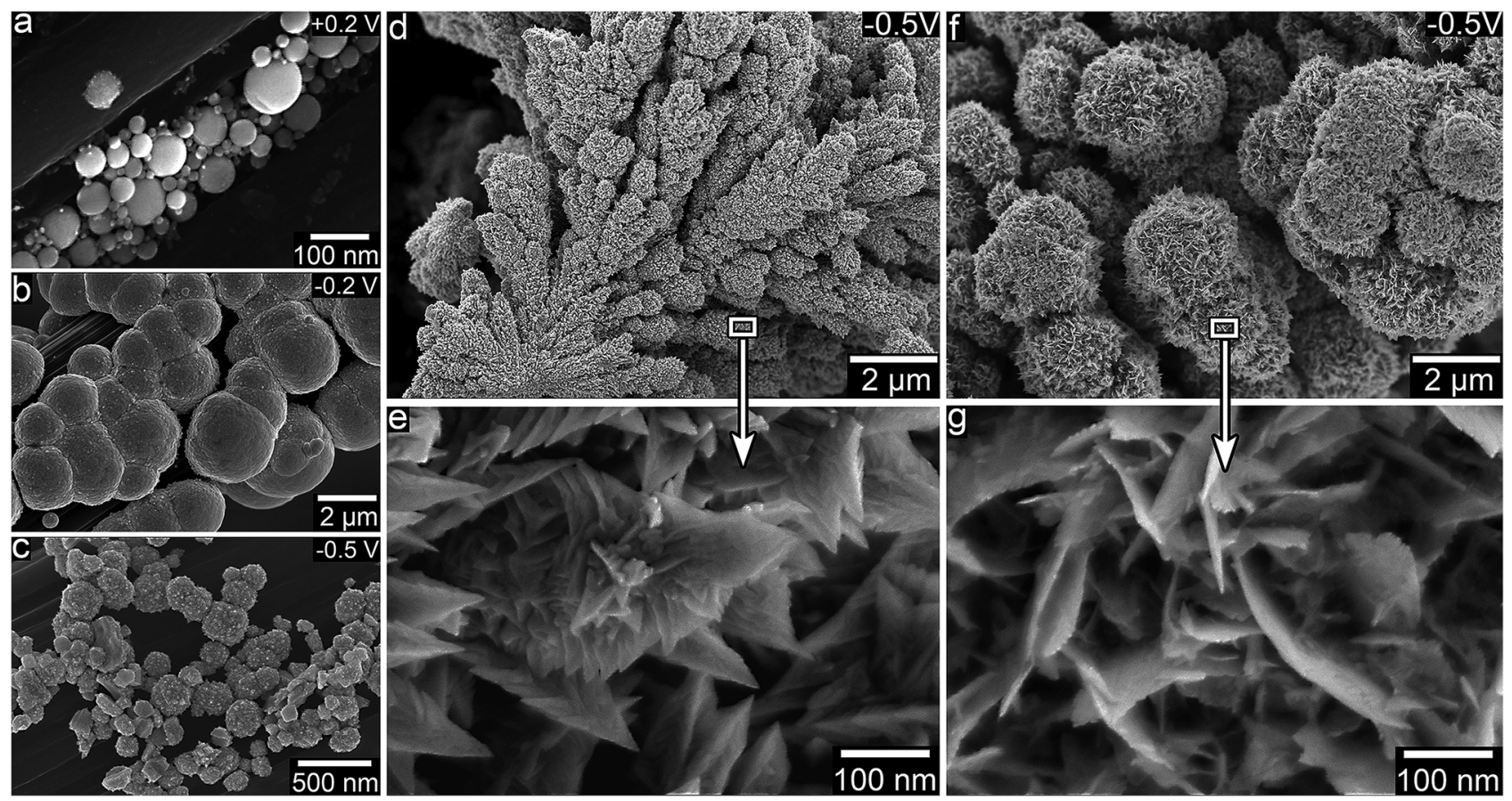

Fig. 5 SEM images of platinum electrodeposited onto carbon fibres in potentiostatic mode for different applied potentials vs. Ag/AgCl after $2 \mathrm{~h}$. 
micron-sized particles, but the higher deposition current of -50 $\mathrm{mA}$ resulted in submicron Pt particles. In agreement with the earlier result, it was apparent that an increase in the deposition current density increased the number density of nucleation sites, and that this led to more and smaller Pt particles with a high specific surface area. ${ }^{59}$ The density of initial nucleation sites on the pristine carbon filament is shown for the $-20 \mathrm{~mA}$ deposition current in Fig. 6f. In Fig. 6b, which shows a magnified region of Fig. 6f, it is evident that the deposition current also had a significant effect on the surface morphology of the Pt particles. A low deposition current gave smooth particle surfaces, but at $-50 \mathrm{~mA}$ a dendritic nanostructure with spiky features was dominant. This nanostructure was discussed earlier in relation to the evolution of hydrogen during the electrodeposition (see the potential level in Fig. 6e). It was, however, apparent that already at a deposition current of -20 $\mathrm{mA}$, smaller grain features favoured particle-to-particle nucleation before new nuclei were formed on the surface of the carbon filaments. This explains the preferred growth of particles on top of previously formed particles visible in Fig. 6f. The higher constant current, $-50 \mathrm{~mA}$, resulted in the most uniform dendritic Pt morphologies along the carbon filaments (Fig. 6c), when the measured potential levelled out at ca. $-0.5 \mathrm{~V} v s . \mathrm{Ag} /$ $\mathrm{AgCl}$, Fig. 6e. These star-shaped morphologies can thus be compared with the mixed morphology (Fig. 5c-g) obtained in the potentiostatic mode at $-0.5 \mathrm{~V}$. Overall, it can be concluded that the carbon filaments dominantly supported a more radial growth of refined nanostructured platinum (and copper) deposits when a higher voltage was used, which agreed with and increased the nucleation on already deposited metal. At the same time, the application of a constant current was the easiest way to reach a more uniform and controlled particle morphology.

Fig. 6d shows the separation of three Pt particles from the carbon fibre surface (grown at $-5 \mathrm{~mA}$ ). The grooves in the filaments are clearly visible as an imprinted and replicated pattern on the released particles. These phase interface fractures were frequently observed and considered detrimental for the targeted catalytic application, although the Pt particles had successfully nucleated on the carbon filaments and grown into the filament grooves. Regardless of the electrodeposition mode, however, the Pt particles never resulted in a complete outer shell covering the high-curvature carbon fibre surfaces, and they always showed inter-particle boundaries due to preferential self-nucleation. This result was in contrast to the copper system and indicated that self-nucleation was greater for the Ption than for the $\mathrm{Cu}$-ion system.

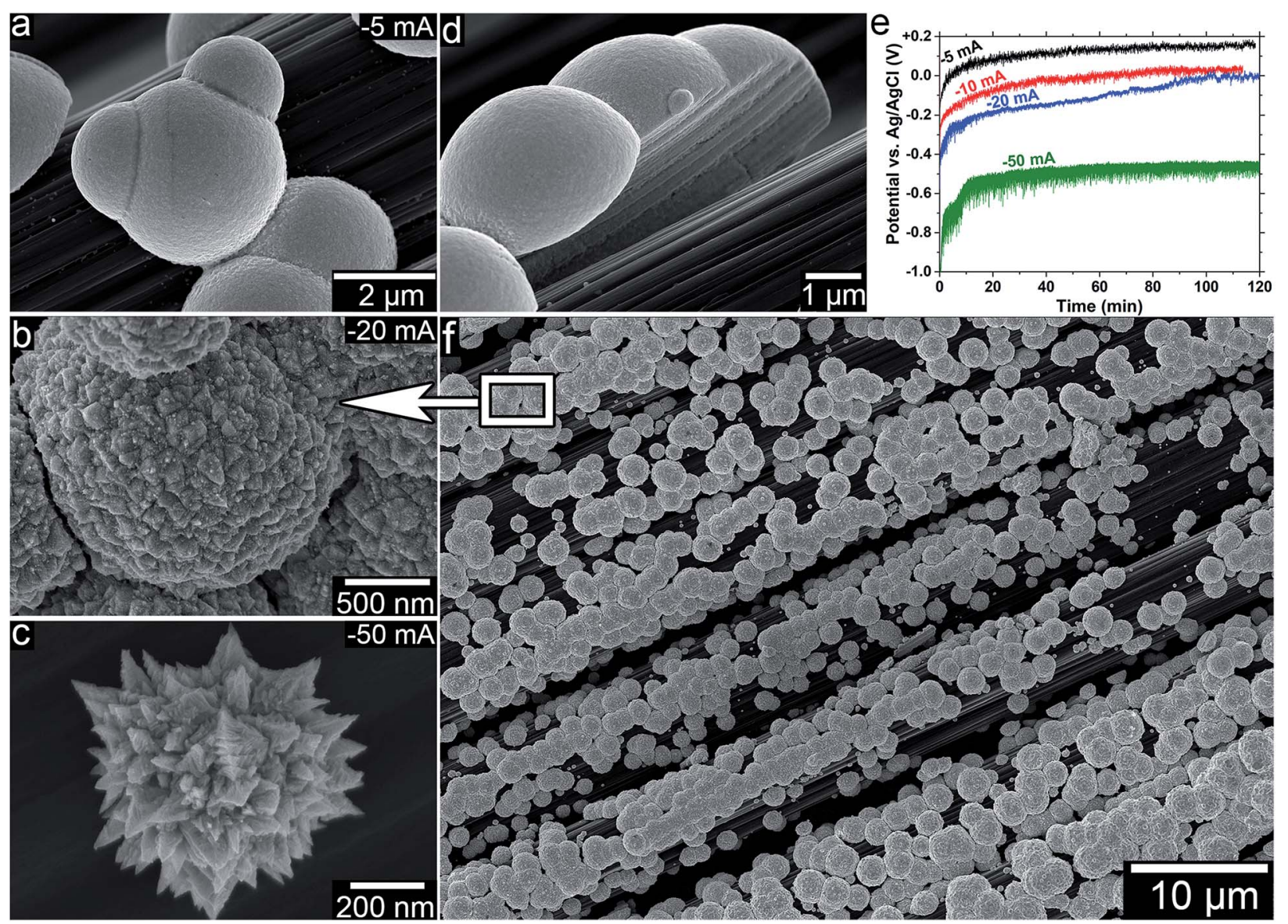

Fig. 6 (a-c and f) SEM images of carbon fibres electrodeposited with platinum in the galvanostatic mode for different applied currents ( -5 , -20 and $-50 \mathrm{~mA}$ ) after $2 \mathrm{~h}$ together with (e) voltage vs. Ag/AgCl-time profiles. (d) SEM image of Pt particles detaching from a carbon fibre surface. 


\subsection{Morphology of copper-platinum ( $\mathrm{Cu}-\mathrm{Pt})$ electrodeposited on carbon fibres}

Since $\mathrm{Cu}$ could effectively stabilize a uniform filament coating, whereas Pt always displayed 'island-like' filaments due to extensive Pt-Pt nucleation instead of a uniform filament coverage, a bimetallic approach was considered based on inspiration by Stamenkovic et al. ${ }^{32}$ Fig. $7 \mathrm{a}$ and b show the $\mathrm{Cu}-\mathrm{Pt}$ coatings electrodeposited in the potentiostatic mode for the deposition potentials of respectively -0.2 and $-0.5 \mathrm{~V}$, after $2 \mathrm{~h}$. The corresponding cathodic current-time profile during $2 \mathrm{~h}$, and the X-ray diffractograms for deposition voltage of $-0.2 \mathrm{~V}$ are shown in Fig. 2e and f. The high magnification micrographs from the $-0.2 \mathrm{~V}$ deposition revealed a nano-sized polycrystalline phase together with submicron crystals (Fig. 7a and d). With an applied voltage of $-0.5 \mathrm{~V}$ (Fig. $7 \mathrm{~b}$ and e), only submicron crystals were formed and the X-ray diffractograms of the $-0.5 \mathrm{~V}$ sample showed only the $\mathrm{Cu} / \mathrm{Cu}_{2} \mathrm{O}$ phase with no sign of $\mathrm{Pt}$ species, Fig. S7.† It was therefore suggested that the facetted submicron crystals in the nanostructured phase obtained at $-0.2 \mathrm{~V}$ consisted mostly of copper (Fig. 7d). Fig. 7c shows that a $-20 \mathrm{~mA}$ electrodeposition current (in the galvanostatic mode) resulted in the aggregation of larger crystals in $1 \mu \mathrm{m}$ lumps.

Overall, the application of a lower voltage $(-0.2 \mathrm{~V})$ resulted in the most uniform filament coverage, completely surrounding the carbon filaments. An average thickness of $c a$. $1 \mu \mathrm{m}$ for $\mathrm{Cu}-\mathrm{Pt}$ deposits on single filaments was estimated from the SEM micrographs, Fig. 7a and f. A uniform coating coverage is considered to be important for the mechanical integrity of the coatings, preventing the release of catalytic metal as was observed with the pure Pt system (Fig. 6d). The cross-section of the bi-metallic coating on the carbon filament interface is shown in Fig. $7 \mathrm{f}-\mathrm{h}$. The $\mathrm{Cu}-\mathrm{Pt}$ coating also showed an ability to orient and fit into carbon fibre surface grooves (observed in Fig. 7f and g), providing an interlock joint system similar to a "dovetail" joint (Fig. $7 \mathrm{~g}$ inset), which hindered detachment of the deposited metal.

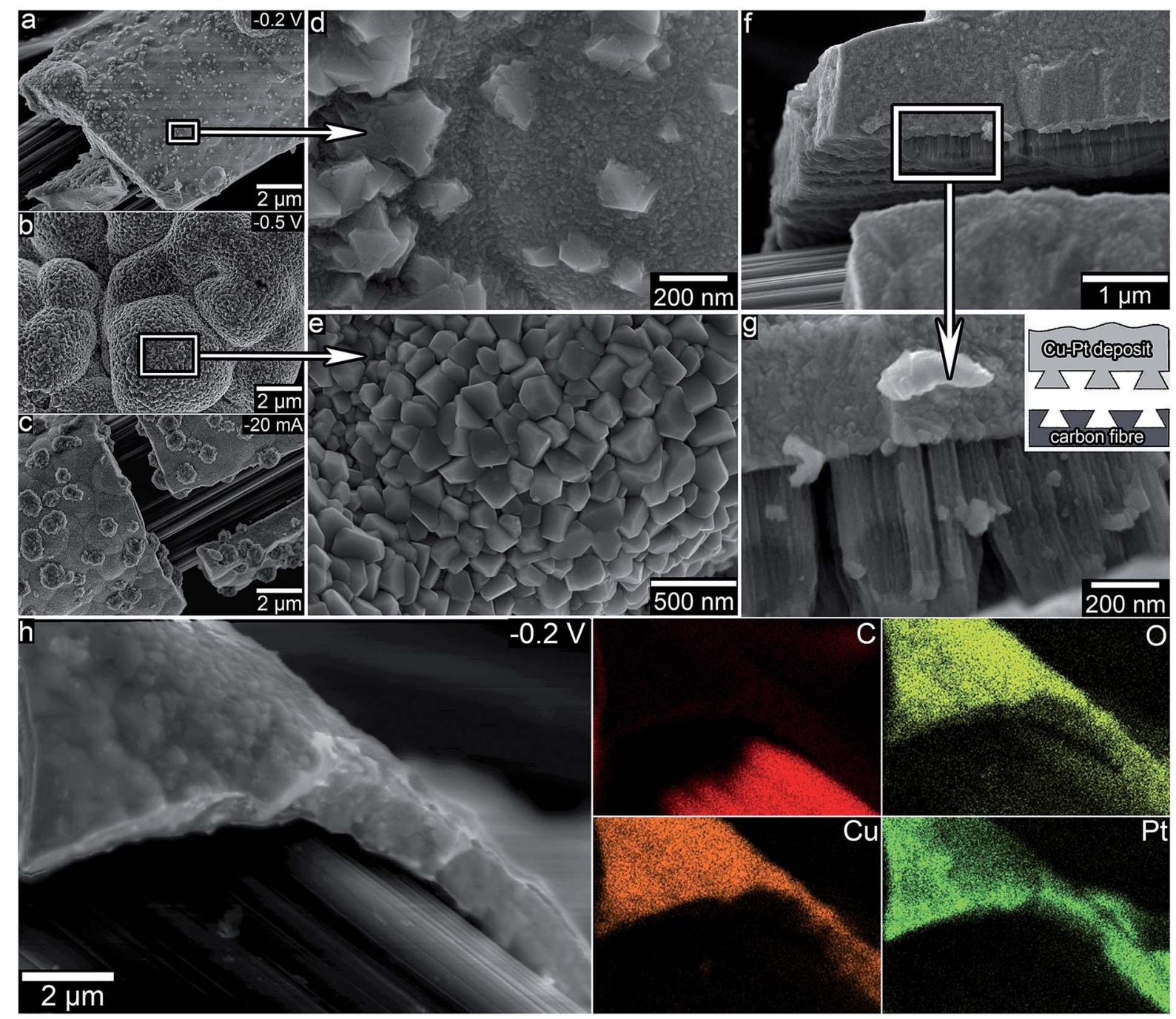

Fig. 7 SEM images of potentiostatic electrodeposited carbon fibres with layers of a binary alloy of copper-platinum after $2 \mathrm{~h}$ (a, b, $\mathrm{d}$, and e); (c) low magnification of the galvanostatic electrodeposition mode; ( $f$ and g) low and high magnifications of the carbon fibre/deposit interface; ( $h$ ) SEM-EDX element mapping of $-0.2 \mathrm{~V}$ electrodeposited sample for carbon (C), oxygen (O), copper (Cu), and platinum (Pt) elements. 
EDX elemental mapping together with SEM was used to study the distribution of elements on the surface and bulk $\mathrm{Cu}-$ $\mathrm{Pt}$ coverage, Fig. 7h. The atomic percentages of $\mathrm{C}, \mathrm{O}, \mathrm{Cu}$ and $\mathrm{Pt}$ were calculated to be 77.1, 15.1, 5.7 and 2.1 respectively. That $\mathrm{Cu}$ and $\mathrm{O}$ were dominant on the surface of the deposits is in agreement with XPS surface analysis, Fig. 3, and these EDX results thus confirmed the ultralow Pt deposition of Pt in the binary system.

\subsection{The catalytic performance of electrodeposited carbon fibres for electro-oxidation of ammonia solution}

The cyclic voltammetry and stepwise chronoamperometry measurements were made for platinum and copper-platinum electrodeposited carbon fibre samples $(2 \mathrm{~h}$ with the potential of $-0.2 \mathrm{~V}$ vs. $\mathrm{Ag} / \mathrm{AgCl}$ ), Fig. 8. The behaviour of the Pt- and $\mathrm{Cu}-\mathrm{Pt}-$ coated carbon fibres in $1 \mathrm{M} \mathrm{KOH}$ is shown in Fig. 8a. For the Ptelectrodeposited sample, the anodic current started on positive scan at $-0.4 \mathrm{~V}$ and reached a peak at $c a$. $-0.14 \mathrm{~V}$, corresponding to the adsorption of $\mathrm{OH}$ on the catalyst surface together with the oxidation associated with the formation of an oxide layer on the platinum surface, occurring in the region from -0.20 to $+0.4 \mathrm{~V} .{ }^{55}$ In the $\mathrm{Cu}-\mathrm{Pt}$ system, the anodic current started earlier at $-0.65 \mathrm{~V}$ and reached a peak at $-0.4 \mathrm{~V}$, which was related to the formation of an oxide layer on copper $\left(\mathrm{Cu}_{2} \mathrm{O}\right)$ in an alkaline $\mathrm{KOH}$ electrolyte. The copper atoms may produce soluble copper hydroxide species at a voltage higher than $0.0 \mathrm{~V}$ during oxidation, ${ }^{65}$ but this did not occur in the $\mathrm{Cu}-\mathrm{Pt}$ system. This supported the hypothesis that the copper atoms were alloyed with the Pt, and was in agreement with the X-ray, XPS and EDX results. This was considered to be important since metallic copper has the potential to contaminate wastewater systems. On negative scanning for the $\mathrm{KOH}$ electrolyte, the cathodic current for the Pt-electrodeposited sample started at $+0.1 \mathrm{~V}$, which was related to the reduction of Pt-oxide, whereas the cathodic current for the $\mathrm{Cu}-\mathrm{Pt}$ system started at $-0.3 \mathrm{~V}$, Fig. 8a. The electrodeposited metals showed a peak between -0.6 and $-0.8 \mathrm{~V}$, which shifted to more negative potentials when the sweep rate was increased, Fig. S8. $\uparrow$ Giri and Sarker ${ }^{65}$ carried out cyclic voltammetry for a copper monolayer on the platinum surface in a $\mathrm{KOH}$ electrolyte and compared the results with those for copper and platinum surfaces. The oxide phase on the monolayer copper and platinum monolayers was reduced at $c a$. -0.25 and $-0.4 \mathrm{~V}$, respectively, ${ }^{65}$ so that the peaks appearing on the negative scan in the -0.6 to $-0.8 \mathrm{~V}$ range should be related to hydrogen adsorption/desorption, which is located in the -0.4 to $-1.0 \mathrm{~V}$ range. The cyclic voltammograms for noble metals within basic electrolytes are characterized by hydrogen adsorption/desorption, double-layer and oxygen regions in potential ranges of respectively $(-1.0$ to $-0.4 \mathrm{~V}),(-0.5$ to -0.2 $\mathrm{V})$ and $(-0.2$ to $+0.6 \mathrm{~V}) .{ }^{55,66}$ The electrochemical active surface area (ECSA) of Pt electrodeposited on a carbon fibre was further derived from the integrated charge of the hydrogen adsorption/ desorption peak (inset in Fig. 8a) divided by the scanning sweep rate and the constant $0.21 \mathrm{in} \mathrm{mC} \mathrm{cm}^{-2}$ (the maximum surface charge transferred to Pt during adsorption of a monolayer of hydrogen). ${ }^{67,68}$ The calculated ECSA was $c a .21 \mathrm{~m}^{2} \mathrm{~g}^{-1}$, which is significantly higher than the value for ordinary electrodes of bulk Pt, Fig. S9a. $\dagger$

Fig. $8 \mathrm{~b}$ shows the cyclic voltammogram of the electrodeposited carbon fibre catalysts in the presence of $0.1 \mathrm{M} \mathrm{NH}_{3}$. The Pt coated carbon fibres showed a broad irreversible anodic peak corresponding to $\mathrm{NH}_{3}$ oxidation with an onset and a maximum at respectively $c a$. -0.8 and $+0.25 \mathrm{~V}$. The maximum current density for electro-oxidation of ammonia was ca. $3 \mathrm{~mA}$ $\mathrm{mg}_{\mathrm{Pt}}{ }^{-1}$ at a sweep rate of $-2 \mathrm{mV} \mathrm{s}^{-1}$, which shifted to a higher positive potential when the scanning rate was increased, see Fig. S8e. $\uparrow$ This maximum current density was much higher than that of pure $220 \mathrm{mg}$ Pt wire (0.5 $\mathrm{mm}$ in diameter). The Pt wire showed a peak current of $3.45 \mathrm{~mA}$ at a potential of $-0.56 \mathrm{~V}$, Fig. S9b, $\dagger$ i.e. ca. $0.02 \mathrm{~mA} \mathrm{mg}_{\mathrm{Pt}}{ }^{-1}$, revealing the importance of the high active surface area achieved using carbon filaments as substrates for the catalytic metal. The onset of electro-oxidation of ammonia on Pt coated filaments $(c a .-0.8 \mathrm{~V}$ ) occurred earlier during cyclic voltammetry than previously reported for the electrodeposited Pt-carbon fibre systems, ${ }^{\mathbf{1 0 , 1 2 , 1 3 , 2 0}}$ (ca. $-0.5 \mathrm{~V}$ ), and less energy was required for the electrolysis. The current density for electro-oxidation of ammonia based on Pt on carbon was previously reported to be $6.5 \mathrm{~mA} \mathrm{mg}_{\mathrm{Pt}}{ }^{-1}$ for carbon fibre paper substrates at a potential of $-0.05 \mathrm{~V} v s$. $\mathrm{Hg} / \mathrm{HgO}$ for $5 \mathrm{M}$ $\mathrm{KOH}$ support electrolyte, but the ammonia concentration was
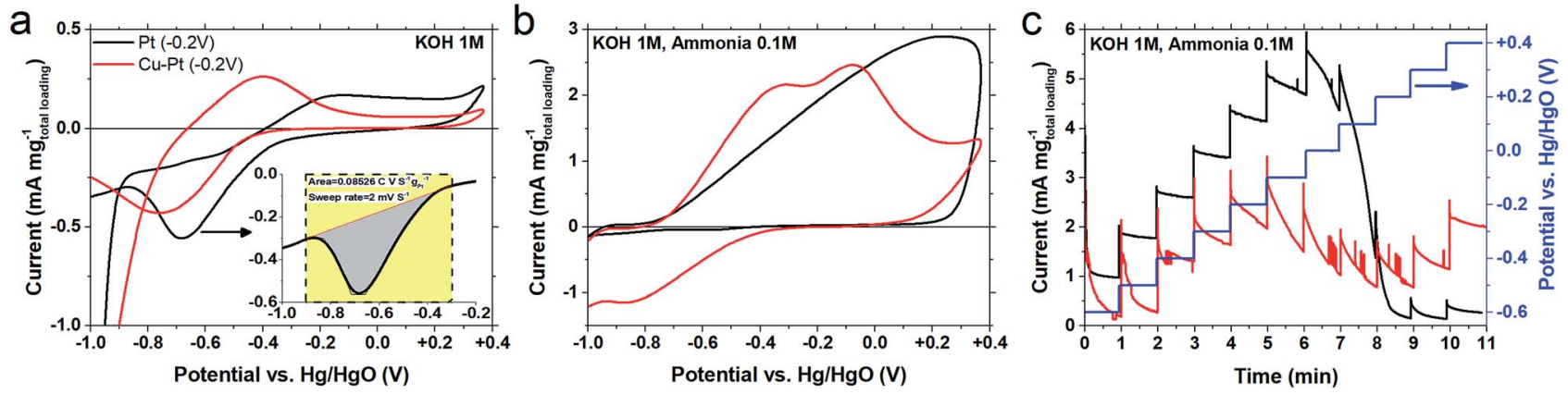

Fig. 8 Electrochemical catalytic activity for different electrodeposited carbon fibre samples; ( $a$ and b) cyclic voltammogram scans in different electrolyte systems with sweep rate of $2 \mathrm{mV} \mathrm{s}^{-1}$ at room temperature, (c) polarization curves with stepwise applied potential with steps of $100 \mathrm{mV}$ at 1 min intervals. The current was normalized with respect to the total mass of deposits including Pt and Cu by measurement of the weight of the carbon fibres before and after electrodeposition. Note: black refers to Pt, red refers to Cu-Pt in all graphs. 
not reported.$^{20}$ Here, a similar current density was achieved at a much lower concentration of $\mathrm{KOH}$ (see Fig. $8 \mathrm{~b}$ and S8†). The same group reported $2.7 \mathrm{~mA} \mathrm{mg}_{\mathrm{Pt}}{ }^{-1}$ at a potential of $+0.1 \mathrm{~V} v s$. $\mathrm{Hg} / \mathrm{HgO}$ for an electrolyte of $1 \mathrm{M} \mathrm{KOH}$ and $1 \mathrm{M}$ ammonia at a sweep rate of $10 \mathrm{mV} \mathrm{s}^{-1} \cdot .^{13}$ Our Pt-carbon electrodes showed ca. $3 \mathrm{~mA} \mathrm{mg}_{\mathrm{Pt}}{ }^{-1}$ under $1 \mathrm{M} \mathrm{KOH}$ conditions, with a 10 times lower ammonia concentration, Fig. S8. $\dagger$ The anodic oxidation of ammonia and the cathodic evolution of hydrogen during cyclic voltammetry on the Pt surfaces is affected by electrolytic parameters and operation conditions, ${ }^{\mathbf{1 2}}$ but ammonia is oxidized more easily at higher $\mathrm{KOH}$ concentrations, which suggests a very high catalytically performance of the Pt-coated filaments with regard to the current density and low onset potential. ${ }^{10}$ The electro-oxidation of ammonia with the binary $\mathrm{Cu}$-Pt system showed an onset at $-0.8 \mathrm{~V}$ and a double peak centred respectively at -0.31 and $-0.06 \mathrm{~V}$ with a maximum current density of $2.5 \mathrm{~mA} \mathrm{mg} \mathrm{Cu}_{\mathrm{Ct} \text { (total loading) }}{ }^{-1}$. The value suggests a slightly lower efficiency of ammonia oxidation than for Pt coated carbon filaments, but it should be noted that the surface-content of noble Pt in this binary system was only $c a$. $3 \mathrm{wt} \%$.

Fig. 8c shows the current density versus time when the potential was increased stepwise in steps of $0.1 \mathrm{~V}$ from $-0.6 \mathrm{~V}$ to $+0.4 \mathrm{~V}$ with an interval of $1 \mathrm{~min}$ for each step. For Pt-coated samples, the current density level increased when the voltage level was increased to $0.0 \mathrm{~V}$, but decreased slowly with time at each voltage step due to the poisoning effect. The electrooxidation of ammonia in basic conditions is a multi-step process involving the successive dehydrogenation of nitrogen species and the formation of a variety of reaction intermediates ${ }^{\mathbf{6 6}, 69}$ which accumulate at the catalyst surface and block the active noble metals sites, i.e. poisoning the main reaction. ${ }^{70}$ The poisoning effect became evident at potentials higher than $0.0 \mathrm{~V}$ for the Pt surface, where the current density decreased for higher potentials. For comparison, the Pt wire with a much lower active surface area was rapidly deactivated due to severe poisoning in the applied potential range, Fig. S9c. $\uparrow$ The $\mathrm{Cu}-\mathrm{Pt}$ binary system showed less poisoning than the pure Pt system at a voltage higher than $\mathrm{ca}$. $0.0 \mathrm{~V}$, Fig. $8 \mathrm{c}$. The severe poisoning of $\mathrm{Pt}$ sites for $\mathrm{ca} .10 \mathrm{~min}$ at the applied potential of $0.0 \mathrm{~V}$ was shown in chronoamperometry tests, Fig S10, $\uparrow$ demonstrating both systems sensitivity to the formation of adsorbed reaction nitrogen intermediates. However, considering the possibility of reactivation of the catalytic surface applying a negative potential, ${ }^{66,69}$ the bimetallic alloy provided an almost similar level of electro-oxidation of wastewater ammonia as when pure Pt was used. It is therefore suggested that the copper hindered the poisoning effect while the low amount of Pt oxidized the ammonia to $\mathrm{N}_{2}$ and $\mathrm{H}_{2}$, since copper alone cannot dehydrogenate $\mathrm{NH}_{3} \cdot{ }^{71}$

Electrodes containing noble metals doped with copper have shown useful activity for methanol electro-oxidation in acidic environments. ${ }^{56,67}$ Here, the successful alloying of the $\mathrm{Cu}$ and $\mathrm{Pt}$ in a superlattice formation can be regarded as beneficial from the perspective of a considerably retarded dissolution of copper during electro-oxidation. ${ }^{54}$

\section{Conclusions}

A novel concept of bimetallic carbon fibre electrodes to be prepared for the purification of wastewater from ammonia contaminant is presented. Only $3 \mathrm{wt} \%$ of platinum was required in a copper superlattice to generate a stable carbon fibre electrode surface with only $30 \%$ less capacity to oxidize ammonia, as compared to the pure platinum. A key component for the exploitation of this effect was to use commercial carbon fibres as an inexpensive electrodeposition material after a thermal shock treatment at $c a .800{ }^{\circ} \mathrm{C}$. The rapid heating allowed their protective polymer coatings to rapidly decompose, while maintaining a high intrinsic filament conductivity of the carbon fibres at $c a .10^{-5} \mathrm{ohm} \mathrm{m}$. Copper, platinum and a combination of copper and platinum ions were deposited on the filaments, and the nature of the metal coatings are corroborated with their methods of deposition as well as the type of metal ions used for similar electroplating conditions. The potentiostatic application of the coatings at higher voltages resulted in complex dendritic morphologies with a very high large surface area but a weak interface towards the filaments, whereas the galvanostatic preparation resulted in more uniform coatings. In contrast to platinum showing a strong preference for deposition on already nucleated surface areas, generating fragile 'islandlike' filament coverage, copper-platinum coatings displayed uniform coating formation surrounding the entire filament cores. The use of carbon fibre filaments for the preparation of catalytic surfaces is expected to find a range of other uses where nanostructured morphologies with large surface area are required for catalytic performance.

\section{Conflicts of interest}

No conflict of interest.

\section{Acknowledgements}

The financial support from Vinnova, the Swedish Agency for Innovation Systems (Ref. 2016-03408), is acknowledged. We also would like to thank the engineering companies Polyproject Environment $\mathrm{AB}$, Mercatus Engineering $\mathrm{AB}$ and the municipal wastewater treatment company SYVAB for their in-kind contributions to this project.

\section{Notes and references}

1 L. Huff, Aquatic Life Ambient Water Quality Criteria for Ammonia-Freshwater 2013, Report EPA 822-R-13-001, U.S. Environmental Protection Agency, Washington, DC, 2013.

2 W. A. Wurts, J. World Aquacult. Soc., 2003, 34, 20-21.

3 WasteWater treatment in Sweden, Swedish Environmental Protection Agency, Stockholm, Sweden, 2009, ISBN number is 978-91-620-8416-5, http://www.naturvardsverket.se/OmNaturvardsverket/Publikationer/ISBN/8400/978-91-620-8416-5/.

4 M. A. H. J. van Kessel, D. R. Speth, M. Albertsen, P. H. Nielsen, H. J. M. Op den Camp, B. Kartal, M. S. M. Jetten and S. Lücker, Nature, 2015, 528, 555-559. 
5 G. Ruiz, D. Jeison and R. Chamy, Water Res., 2003, 37, 13711377.

6 R. Hatzenpichler, Appl. Environ. Microbiol., 2012, 78, 75017510.

7 Y. Li, K. Ding, X. Wen, B. Zhang, B. Shen and Y. Yang, Sci. Rep., 2016, 6, 23747.

8 P. Ciambelli, P. Corbo, C. Porcelli and A. Rimoli, Zeolites, 1985, 5, 184-187.

9 T. C. Jorgensen and L. R. Weatherley, Water Res., 2003, 37, 1723-1728.

10 J. Gwak, M. Choun and J. Lee, ChemSusChem, 2016, 9, 403408.

11 L. Li, J. Yao, X. Fang, Y. Huang and Y. Mu, Sci. Rep., 2017, 7, 41030.

12 C. Zhong, W. B. Hu and Y. F. Cheng, J. Mater. Chem. A, 2013, 1, 3216-3238.

13 E. P. Bonnin, E. J. Biddinger and G. G. Botte, J. Power Sources, 2008, 182, 284-290.

14 D. J. Little, I. I. I. M. R. Smith and T. W. Hamann, Energy Environ. Sci., 2015, 8, 2775-2781.

15 G. Zhang, Y. Zhou and F. Yang, Electrochim. Acta, 2019, 299, 672-681.

16 A. M. Pourrahimi and M. Pumera, Nanoscale, 2018, 10, 16398-16415.

17 A. M. Pourrahimi, K. Villa, C. L. Manzanares Palenzuela, Y. Ying, Z. Sofer and M. Pumera, Adv. Funct. Mater., 2019, 1808678.

18 A. M. Pourrahimi, K. Villa, Y. Ying, Z. Sofer and M. Pumera, ACS Appl. Mater. Interfaces, 2018, 10, 42688-42697.

19 B. K. Boggs and G. G. Botte, J. Power Sources, 2009, 192, 573581.

20 B. K. Boggs and G. G. Botte, Electrochim. Acta, 2010, 55, 52875293.

21 K. Endo, Y. Katayama and T. Miura, Electrochim. Acta, 2004, 49, 1635-1638.

22 K. Siddharth, Y. Chan, L. Wang and M. Shao, Curr. Opin. Electrochem., 2018, 9, 151-157.

23 Y. Zhou, G. Zhang, M. Yu, J. Xu, S. Qiao, X. Cheng and F. Yang, ChemistrySelect, 2018, 3, 3433-3443.

24 N. Sacré, M. Duca, S. Garbarino, R. Imbeault, A. Wang, A. Hadj Youssef, J. Galipaud, G. Hufnagel, A. Ruediger, L. Roué and D. Guay, ACS Catal., 2018, 8, 2508-2518.

25 Y. Liu, B. Huang and Z. Xie, Appl. Surf. Sci., 2018, 427, 693701.

26 B. Huang, Y. Liu and Z. Xie, J. Mater. Chem. A, 2017, 5, 2348123488.

27 B. Huang, Y. Liu, X. Huang and Z. Xie, J. Mater. Chem. A, 2018, 6, 22277-22286.

28 B. Huang, X. Hu, Y. Liu, W. Qi and Z. Xie, J. Power Sources, 2019, 413, 408-417.

29 M. Wu, J. Du, C. Tao, Z. Liu and Y. Li, J. Colloid Interface Sci., 2019, 542, 451-459.

30 I. Lucentini, A. Casanovas and J. Llorca, Int. J. Hydrogen Energy, 2019, 44, 12693-12707.

31 Y. Liu, B. Huang, X. Zhang, X. Huang and Z. Xie, J. Power Sources, 2019, 412, 125-133.
32 V. R. Stamenkovic, B. S. Mun, M. Arenz, K. J. J. Mayrhofer, C. A. Lucas, G. Wang, P. N. Ross and N. M. Markovic, Nat. Mater., 2007, 6, 241.

33 Y. Liu, B. Huang, X. Hu and Z. Xie, Int. J. Hydrogen Energy, 2019, 44, 3702-3710.

34 J. Hagberg, S. Leijonmarck and G. Lindbergh, J. Electrochem. Soc., 2016, 163, A1790-A1797.

35 M. MInus and S. Kumar, JOM, 2005, 57, 52-58.

36 R. Yu, L. Chen, Q. Liu, J. Lin, K.-L. Tan, S. C. Ng, H. S. O. Chan, G.-Q. Xu and T. S. A. Hor, Chem. Mater., 1998, 10, 718-722.

37 S. H. Joo, S. J. Choi, I. Oh, J. Kwak, Z. Liu, O. Terasaki and R. Ryoo, Nature, 2001, 412, 169-172.

38 H. Yang-Chih, W. Chih-Chieh, L. Chueh, K. Chi-Chung and P. Tsong-Pyng, Nanotechnology, 2012, 23, 405603.

39 R. D. Sanderson and E. R. Sadiku, J. Appl. Polym. Sci., 2003, 87, 1051-1058.

40 S. Song, C. M. Ortega, Z. Liu, J. Du, X. Wu, Z. Cai and L. Sun, J. Electroanal. Chem., 2013, 690, 53-59.

41 B. Pierozynski, Croat. Chem. Acta, 2012, 85, 1-8.

42 A. Subrenat, L. M. Le Leuch and P. Le Cloirec, Environ. Technol., 2008, 29, 993-1000.

43 P. E. Larson and M. A. Kelly, J. Vac. Sci. Technol., A, 1998, 16, 3483-3489.

44 A. Sumida and S. Watanabe, US Pat. 4555446 A, 1985.

45 T. R. Pozegic, J. V. Anguita, I. Hamerton, K. D. G. I. Jayawardena, J. S. Chen, V. Stolojan, P. Ballocchi, R. Walsh and S. R. P. Silva, Sci. Rep., 2016, 6, 37334.

46 P. Mitschang, M. Blinzler and A. Wöginger, Compos. Sci. Technol., 2003, 63, 2099-2110.

47 A. K. Dutta, Phys. Rev., 1953, 90, 187-192.

48 D. Grujicic and B. Pesic, Electrochim. Acta, 2002, 47, 29012912.

49 B. E. Conway, H. Angerstein-Kozlowska, W. B. A. Sharp and E. E. Criddle, Anal. Chem., 1973, 45, 1331-1336.

50 A. Mallik and B. C. Ray, Mater. Res., 2013, 16, 539-545.

51 A. Lalitha, S. Ramesh and S. Rajeswari, Electrochim. Acta, 2005, 51, 47-55.

52 A. M. Pourrahimi, D. Liu, V. Ström, M. S. Hedenqvist, R. T. Olsson and U. W. Gedde, J. Mater. Chem. A, 2015, 3, 17190-17200.

53 S. Akhlaghi, A. M. Pourrahimi, C. Sjöstedt, M. Bellander, M. S. Hedenqvist and U. W. Gedde, Polym. Degrad. Stab., 2017, 138, 27-39.

54 N. Jung, Y. Sohn, J. H. Park, K. S. Nahm, P. Kim and S. J. Yoo, Appl. Catal., B, 2016, 196, 199-206.

55 M. H. M. T. Assumpção, R. M. Piasentin, P. Hammer, R. F. B. De Souza, G. S. Buzzo, M. C. Santos, E. V. Spinacé, A. O. Neto and J. C. M. Silva, Appl. Catal., B, 2015, 174-175, 136-144.

56 X. Du, S. Luo, H. Du, M. Tang, X. Huang and P. K. Shen, J. Mater. Chem. A, 2016, 4, 1579-1585.

57 S. Li, R. Furberg, M. S. Toprak, B. Palm and M. Muhammed, Adv. Funct. Mater., 2008, 18, 2215-2220.

58 L. Zheng, D. Yang, R. Chang, C. Wang, G. Zhang and S. Sun, Nanoscale, 2017, 9, 8918-8924. 
59 J. Liu, C. Zhong, Y. Yang, Y. T. Wu, A. K. Jiang, Y. D. Deng, Z. Zhang and W. B. Hu, Int. J. Hydrogen Energy, 2012, 37, 8981-8987.

60 J. L. Castro-Mayorga, M. J. Fabra, A. M. Pourrahimi, R. T. Olsson and J. M. Lagaron, Food Bioprod. Process., 2017, 101, 32-44.

61 A. M. Pourrahimi, T. A. Hoang, D. Liu, L. K. Pallon, S. Gubanski, R. T. Olsson, U. W. Gedde and M. S. Hedenqvist, Adv. Mater., 2016, 28, 8651-8657.

62 A. M. Pourrahimi, D. Liu, R. L. Andersson, V. Ström, U. W. Gedde and R. T. Olsson, Langmuir, 2016, 32, 1100211013.

63 F. J. Vidal-Iglesias, N. García-Aráez, V. Montiel, J. M. Feliu and A. Aldaz, Electrochem. Commun., 2003, 5, 22-26.

64 A. M. Pourrahimi, R. T. Olsson and M. S. Hedenqvist, Adv. Mater., 2018, 30, 1703624.
65 S. D. Giri and A. Sarkar, J. Electrochem. Soc., 2016, 163, H252H259.

66 S. Le Vot, D. Reyter, L. Roué and D. Bélanger, J. Electrochem. Soc., 2012, 159, F91-F96.

67 C. Wang, F. Ren, C. Zhai, K. Zhang, B. Yang, D. Bin, H. Wang, P. Yang and Y. Du, RSC Adv., 2014, 4, 57600-57607.

68 Y. Holade, T. W. Napporn, C. Morais, K. Servat and K. B. Kokoh, ChemElectroChem, 2015, 2, 592-599.

69 H. Gerischer and A. Mauerer, J. Electroanal. Chem. Interfacial Electrochem., 1970, 25, 421-433.

70 F. Vitse, M. Cooper and G. G. Botte, J. Power Sources, 2005, 142, 18-26.

71 A. C. A. de Vooys, M. T. M. Koper, R. A. van Santen and J. A. R. van Veen, J. Electroanal. Chem., 2001, 506, 127-137. 